\title{
Sleepiness after Stroke: Case Report and Review of Literature on Hypersomnia as a Result of Stroke
}

\author{
Pradeep C. Bollu ${ }^{1}$, Ashutosh Pandey ${ }^{2}$, Siva Prasad Pesala ${ }^{3}$ and Krishna Nalleballe ${ }^{1 \star}$ \\ ${ }^{1}$ Assistant Professor, Department of Neurology, University of Missouri, Columbia, USA \\ ${ }^{2}$ Albert Einstein School of Medicine, Bronx NY, USA \\ ${ }^{3}$ Neurologist, Department of Neurology, University of Missouri, Columbia, USA
}

\section{Article Info}

\section{*Corresponding author: \\ Krishna Nalleballe \\ Assistant Professor \\ Department of Neurology \\ University of Missouri, Columbia 65212, USA \\ Tel. 6032897308/5738821515 \\ E-mail: pradeepontheweb@gmail.com}

Received: March 16, 2017

Accepted: March 23, 2017

Published: March 28, 2017

Citation: Bollu CP, Pandey A, Pesala SP, Nalleballe K. Sleepiness after Stroke: Case Report and Review of Literature on Hypersomnia as a Result of Stroke. Madridge J Neurosci. 2017; 1(1): 4-6.

doi: 10.18689/mjns-1000102

Copyright: @ 2017 The Author(s). This work is licensed under a Creative Commons Attribution 4.0 International License, which permits unrestricted use, distribution, and reproduction in any medium, provided the original work is properly cited.

Published by Madridge Publishers
Keywords: Hypersomnia; Stroke; Daytime sleepiness; Conventional angiogram.

Abbreviations: MRA: Magnetic resonance angiography; MRI: Magnetic resonance imaging; PLMS: Periodic limb movements in sleep; NREM: Non rapid eye movement; SDB: Sleep disordered breathing

\section{Introduction}

Daytime sleepiness is defined as the inability to stay awake and alert during the major waking episode of the day resulting in irrepressible need for sleep or unintended lapses into drowsiness. Excessive sleepiness affects up to $5 \%$ of the general population and can result in significant disability. Hypersomnia can be either the result of unmet sleep needs or can also be due to reduced activity of alerting systems in the brain. The former can be due to sleep restriction or from sleep disruption. The International Classification of Sleep disorders categorize various disorders of hyper somnolence into different sub-groups. Exaggerated sleep propensity with daytime sleepiness and/ or prolonged nocturnal sleep following cerebrovascular accident falls under 'Hypersomnia due to a medical disorder'. Sleepiness after stroke is a rare complication but when it happens, can be disabling to the patients. Hypersomnia may have worse outcomes than apathy [1] in stroke patients.

The exact frequency of hypersomnia after stroke is unknown though in a few studies, it is seen up to 1.1 to $27 \%$ of the patients. The severity of sleepiness following stroke can be very mild or can be severe and can be transient or permanent. The location of the stroke and in some cases, the size of the stroke is the major determinant of the nature of the hypersomnia that follows the stroke. In this article, we describe a case of an elderly female who developed severe sleepiness after having a stroke in bilateral Para median thalamic region and also review the literature on sleepiness as a delayed complication of stroke.

\section{Case Report}

An 87-year-old female was taken to an outside hospital for acute onset of somnolence. Her past medical history is significant for hypertension and diabetes mellitus. Magnetic resonance imaging (MRI) of the brain performed at the outside facility showed the presence of bilateral thalamic and sub-thalamic infarctions (Figure 1). Magnetic resonance angiography (MRA) did not reveal anomalous vasculature in the posterior circulation though the patient did not undergo conventional angiogram at that time. The patient was drowsy for the first few days but improved gradually during the hospital stay. During the hospital course, both the patients and the relatives reported 
significant reduction in her hand tremor for which she had been on propranolol. She started to experience sleepiness in the next few weeks, which persisted subsequently.

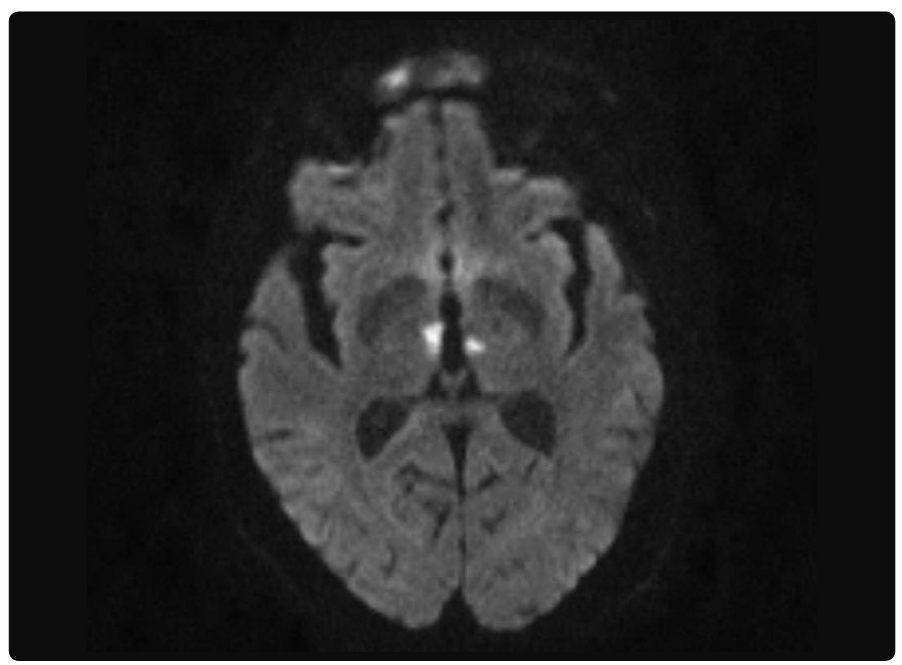

Figure 1: Restricted diffusion in the diffusion weighted sequence of MRI in the bilateral Para median thalamus.

\section{Historical Aspects}

MacNish in 1830 first mentioned the increased sleepiness following stroke [2]. The association of sleep-wake disorders in patients with cerebrovascular accidents became increasingly reported from the beginning of the $20^{\text {th }}$ century. Carl Wernicke [3] reported occasional occurrence of impaired consciousness in patients who had punctate hemorrhages in gray matter around third and fourth ventricles. He called it 'Polio encephalitis hemorrhagica superioris' and we now call it 'Wernicke-Korsakoff syndrome. Von Economo showed the presence of posterior hypothalamic lesions in patients with hypersomnia [4]. Later, Hess's [5] observation of sleep induction in Cats following low frequency stimulation of the medial thalamus suggested the role of the thalamus in sleep generation.

\section{Stroke and its Relationship with Sleep and Sleep Disorders}

Sleep has protective effect against strokes and hence the incidence of stroke increases in sleep disorders. Sleep wake cycle is regulated by a complex interaction of various different areas of the brain like brainstem, hypothalamus, thalamus and preoptic region. This is why focal lesions in these regions result in sleep disorders. Stroke patients who experience sleep disorders can range anywhere from 20 to $63 \%$ [6]. A wide range of sleep disorders can be seen in stroke patients including hypersomnia, insomnia, parasomnias, periodic limb movements in sleep (PLMS) and sleep related breathing disorders. The presence of sleep disorders in stroke patients may be associated with increased mortality and poorer prognosis [7]. Strokes can also affect the sleep architecture. A stroke in the supratentorial region has been linked with decrease in total sleep time with a reduction of Non Rapid Eye Movement (NREM) sleep [8]. There may be ipsilateral or bilateral reduction in sleep spindles after a hemispheric stroke [9]. Temporary reduction in Rapid Eye Movement (REM) sleep may also be observed in some cases of supratentorial stroke. This is more frequent with right-sided strokes. The saw tooth wave may be reduced after hemispheric stroke [10]. Occipital stroke can reduce REM sleep [11]. Strokes in pontomesencephalic junction and the Raphe nucleus may diminish NREM sleep while not affecting the amount of REM sleep. There may be REM sleep onset at the beginning of the sleep cycle. At the same time, strokes in lower pons may reduce REM sleep selectively [12-15]. Para median thalamus and lower pontine strokes can result in lack of slow wave sleep and preserved REM sleep. Ponto medullary junction and mesencephalic tegmental strokes may increase REM sleep [6] whereas infarcts in the midbrain can result in increases in both NREM and REM sleep [16].

Insomnia is common in stroke patients and affects 20$56 \%$ of stroke patients (higher incidence than hypersomnia). About $18 \%$ of people reported new onset insomnia after the stroke. Insomnia typically occurs in the acute phases of the stroke. Thalamic and brainstem (thalamomesencephalic, pontomesencephalic and pontine tegmental) strokes can present with insomnia $[7,17]$.

Various parasomnias like REM sleep behavior sleep disorders (RBD) have been described with tegmental pontine strokes, strokes in the thalamus and in the temporal, parietal, and occipital lobes. In one case report, pontine stroke was associated with isolated cataplexy and REM sleep behavior disorder [18].

Denovo leg syndromes were reported to be as high as $12 \%$ in all stroke patients [19]. Restless leg syndrome was reported in strokes involving pons, thalamus, basal ganglia and corona radiata. About $2 / 3^{\text {rd }}$ of those restless leg syndrome patients reported bilateral symptoms while $1 / 3^{\text {rd }}$ reported symptoms on the side opposite to the stroke [6].

Sleep disordered breathing (SDB) can be seen in as high as 50 to $70 \%$ in stoke patients [20]. Not only does SDB increase the risk for stroke, stroke also can result SDB. Both obstructive sleep apnea and central sleep apnea have been reported widely after stroke. Identifying the occurrence of sleepdisordered breathing is an important component of primary or secondary stroke prevention

The most severe cases of hyper somnolence secondary to stroke are caused by Para median thalamic infarctions. A case of Kleine-Levin syndrome was also reported after multiple cerebral infarctions [21]. Narcolepsy with low CSF hypocretin levels was reported in a case after diencephalic stroke [22]. Circadian rhythm disturbances were noted after modafinil treatment in a patient with bilateral thalamic stroke related sleepiness [23].

\section{Mechanism of Hypersomnia after Stroke}

A reduction in the activity of the arousal system (dearousal) underlies most forms of post stroke hypersomnia [24]. Bilateral lesions of posterior hypothalamus, tegmental midbrain and 
upper pons tend to cause severe forms of hyper somnolence as fibers of arousal systems are bundled and can be affected by a single lesion. The mental arousal seems more affected by medial lesions whereas the lateral lesions tend to affect motor arousal preferentially [25]. Other areas that may occasionally cause hypersomnia are stratum, pontine tegmentum, medulla and cerebral hemisphere (if large area is involved). It is seen that hemisphere strokes resulting in hypersomnia tend to be more on the left side than right and anterior more than posterior. Cortical and subcortical strokes can also cause post stroke hypersomnia but with wide variability which may be related to a relatively less compact arousal pathways with respect to the brainstem.

\section{Conclusion}

Sleepiness following stroke is an under-recognized complication and can affect up to a quarter of stroke patients with a severity ranging from mild to very severe. Patients with hypersomnia after stroke are 10 times more likely go to nursing home compared to those who do not have hypersomnia. The recovery from hypersomnia is very variable with most cases improving in the first few days. However, hypersomnia can persist for years and can evolve into akinetic mutism. Therapy is often ineffective [6] in the patients who are affected severely. Multiple medications including amphetamine salts, modafinil, methylphenidate, levodopa, bromocriptine have been tried with variable success. Prompt recognition of this complication and a thorough sleep evaluation can lower the morbidity and improve patient outcomes [26].

\section{References}

1. Harris AL, Elder J, Schiff ND, Victor JD, Goldfine AM. Post-stroke apathy and hypersomnia lead to worse outcomes from acute rehabilitation. Translational stroke research. 2014. 5(2): 292-300. doi: 10.1007/s12975013-0293-y PMCID: PMC2375184

2. Macnish R. The philosophy of sleep. Appleton. $1^{\text {st }}$ ed. New York, USA: 1834.

3. Wernicke $C$. Lehrbuch der gehirnkrankheiten für aerzte und studirende. Kassel [etc.] Fischer. 1881; 1848-1905.

4. Saper CB, Scammell TE, Lu J. Hypothalamic regulation of sleep and circadian rhythms. Nature. 2005; 437(7063): 1257-1263. doi: 10.1038/ nature04284

5. Hess W. Hirnreizversuche über den Mechanismus des Schlafes. Arch Psychiat Nervenkrankh. 1929; 86: 287-292.

6. Ferre $A$, Ribó $M$, Rodríguez-Luna $D$, et al. Strokes and their relationship with sleep and sleep disorders. Neurología. 2013; 28(2): 103-118. doi: 10.1016/j.nrl.2010.09.016.

7. Bassetti CL. Sleep and stroke. Semin Neurol. 2005; 25(1): 19-32. doi: $10.1055 / \mathrm{s}-2005-867073$

8. Gasanov RL, Gitlevich TR, Lesnyak VN, Levin Yal. Structure of nocturnal sleep in patients with cerebral insult. Neurosci Behav Physiol. 1998; 28(3): 325-329.

9. Vock J, Achermann P, Bischof M, et al. Evolution of sleep and sleep EEG after hemispheric stroke. J Sleep Res. 2002; 11(4): 331-338. doi: 10.1046/j.1365-2869.2002.00316.x

10. Bassetti $C L$, Aldrich MS. Sleep electroencephalogram changes in acute hemispheric stroke. Sleep med. 2001; 2(3): 185-194. doi: 10.1016/S13899457(00)00071-X
11. Appenzeller $\mathrm{O}$, Fischer $\mathrm{A}$. Disturbances of rapid eye movements during sleep in patients with lesions of the nervous system. Electroencephalography and Clinical Neurophysiology. 1968; 25(1): 2935. doi: 10.1016/0013-4694(68)90083-7

12. Markand ON, Dyken ML. Sleep abnormalities in patients with brain stem lesions. Neurology. 1976; 26(8): 769-769.

13. Valldeoriola F, Santamaria J, Graus F, Tolosa E. Absence of REM sleep, altered NREM sleep and supranuclear horizontal gaze palsy caused by a lesion of the pontine tegmentum. Sleep. 1993; 16(2): 184-188.

14. Tamura K, Karacan I, Williams RL, Meyer JS. Disturbances of the sleepwaking cycle in patients with vascular brain stem lesions. Clin Electroencephalogr. 1983; 14(1): 35-46.

15. Autret A, Laffont F, de Toffol B, Cathala HP. A syndrome of REM and non-REM sleep reduction and lateral gaze paresis after medial tegmental pontine stroke: Computed tomographic scans and anatomical correlations in four patients. Archives of neurology. 1988; 45(11): 12361242.

16. Bassetti. Principles and Practice of Sleep medicine. $4^{\text {th }}$ ed. 2005: 811-832.

17. Leppävuori A, Pohjasvaara $T$, Vataja R, Kaste M, Erkinjuntti T. Insomnia in ischemic stroke patients. Cerebrovasc Dis. 2002; 14(2): 90-97.

18. Reynolds TQ, Roy A. Isolated cataplexy and REM sleep behavior disorder after pontine stroke. J Clin Sleep Med. 2011; 7(2): 211-213.

19. Lee SJ, Kim JS, Song IU, An JY, Kim YI, Lee KS. Poststroke restless legs syndrome and lesion location: anatomical considerations. Movement Disorders. 2009; 24(1): 77-84. doi: 10.1002/mds.22303.

20. Turkington P, Bamford J, Wanklyn P, Elliott MW. Prevalence and predictors of upper airway obstruction in the first 24 hours after acute stroke. Stroke. 2002; 33(8): 2037-2042.

21. Drake ME. Kleine-Levin syndrome after multiple cerebral infarctions. Psychosomatics. 1987; 28(6): 329-330. doi: 10.1016/S00333182(87)72524-9

22. Scammell T, Nishino S, Mignot E, Saper CB. Narcolepsy and low CSF orexin (hypocretin) concentration after a diencephalic stroke. Neurology. 2001; 56(12): 1751-1753.

23. Zavalko I, Bassetti CL, Cianfoni $A$, Carugati J, Fulda S, Manconi M Hypersomnia due to bilateral thalamic lesions: unexpected response to Modafinil. European journal of neurology. 2012; 19(11): e125. doi: 10.1111/j.1468-1331.2012.03835

24. Bassetti CL, Valko P. Poststroke hypersomnia. Sleep Medicine Clinics. 2006; 1(1): 139-155.

25. Castaigne P, Escourolle R. Hypersomnies. 1967; 116: 547-584.

26. Jang $\mathrm{SH}$, Lee HD, Chang $\mathrm{CH}$, Jung YJ. Recovery of Hypersomnia Concurrent With Recovery of an Injured Ascending Reticular Activating System in a Stroke Patient: A Case Report. Medicine. 2016; 95(2): e2484. doi: 10.1097/MD.0000000000002484. 